\title{
SEED: a tool for disseminating systematic review data into Wikipedia
}

\author{
Lena Schmidt ${ }^{1}$, Johannes Friedel ${ }^{1}$ and Clive E. Adams ${ }^{2,3^{*}}$
}

\begin{abstract}
Wikipedia, the free-content online encyclopaedia, contains many heavily accessed pages relating to healthcare. Cochrane systematic reviews contain much high-grade evidence but dissemination into Wikipedia has been slow. New skills are needed to both translate and relocate data from Cochrane reviews to implant into Wikipedia pages. This letter introduces a programme to greatly simplify the process of disseminating the summary of findings of Cochrane reviews into Wikipedia pages.
\end{abstract}

Keywords: Wikipedia, Summary of findings, Automation, Systematic reviews, Reducing waste

\section{Background}

Wikipedia contains over 40 million articles with $5.3 \mathrm{~m}$ in the English language [1]. Since its creation in 2001, Wikipedia has expanded to attract over 374 million unique visitors each month and around $20 \%$ of healthcare-related online searches direct to Wikipedia pages $[2,3]$. Every year health pages on Wikipedia receive over 4.8 billion views [4]. Wikipedia is openly editable so any user can access and edit the majority of articles. Wikipedia policy states, however, that all information presented in pages must be "verifiable against a published reliable source" [5].

The Cochrane Collaboration is a non-for profit organisation producing, and maintaining systematic reviews of health care [6]. A systematic review "attempts to collate all empirical evidence that fits pre-specified eligibility criteria in order to answer a specific research question. It uses explicit, systematic methods that are selected with a view to minimising bias, thus providing more reliable findings from which conclusions can be drawn and decisions made" [7]. These findings are acceptable on Wikipedia pages if referenced and reliable. The Cochrane Collaboration uses a writing tool-RevMan [8] - to produce its reviews but disseminating the findings of the reviews within Wikipedia necessitates more work. Data have to be extracted, summarised and

\footnotetext{
* Correspondence: clive.adams@nottingham.ac.uk

¿University of Nottingham, Nottingham, UK

${ }^{3}$ Institute of Mental Health, Jubilee Campus, University of Nottingham

Innovation Park, Triumph Road, Nottingham NG7 2TU, UK

Full list of author information is available at the end of the article
}

referenced in the clear and simple way required by Wikipedia. This additional effort and skill set often results in Cochrane reviews being less used in Wikipedia pages than could be the case.

\section{Aim}

To produce a tool (Systematic EvidEnce Disseminator, SEED) to auto-generate a Wikipedia-compatible table and accompanying reference direct from Cochrane's RevMan files.

\section{Procedure}

The programme was created by students of Applied Health Science with close-to-zero previous knowledge in programming and the help of printed popular texts [9], numerous YouTube tutorials and internet fora. For creating the SEED tool, the integrated development environment 'Eclipse' was used (Neon version) [9]. This open-source programme allows the developed application to run on the programming language Java.

RevMan (v5.3) is an open-access text editor for authors of reviews [8]. It produces structured XML (Extensible Markup Language) review files (.rm5) within which Summary of Findings tables (SoF) - in turn produced by GradePro [10] - are embedded. Because the development team worked within Cochrane Schizophrenia's editorial base they had access to RevMan files. The team had identified Wikipedia pages specific enough to be appropriately seeded with evidence from particular reviews' SoF tables [11]. 


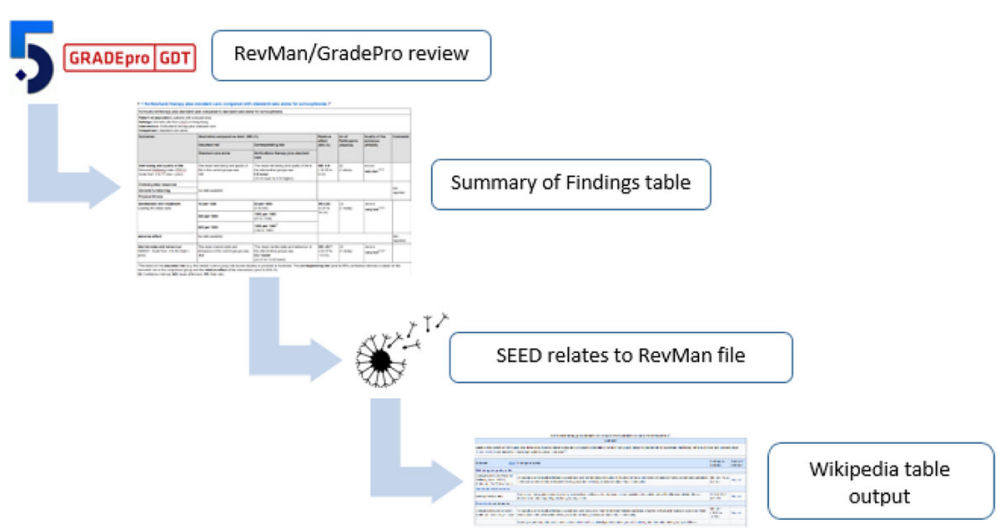

Fig. 1 Information flow diagram

Because each .rm5 file has basically the same structure, this makes it simple to read content automatically. Eclipse parses the XML structure with its 'chapters' and 'subchapters' (children). The parser programme reads and follows relevant roots of XML-format and can jump to the SoF tables section and the references. In combination with the code we generated to parse through the files attributes or elements of the SoF part of the XML file can be converted into 'strings' and these, in turn, embedded in prepared phrases. These phrases were developed with the help of Sense about Science [12], to ensure both accuracy and clarity for Wikipedia readers. After SEED captures the SoF content, it converts it into the special format of Wikipedia tables. This format is standardised [13] and includes code for generating the correct size, font, formatting, colour and shading. We used Swing [14] to build the graphical interface of SEED. Swing is a GUI (Graphical user interface) tool allowing those with low IT knowledge to create a typical window with buttons, text fields and icons.

\section{Output}

SEED allows the user to select their RevMan file, choose the relevant SoF table, and then produce compatible Code of Wikipedia tables (Fig. 1) that can be pasted directly into the editing box of the relevant Wikipedia page. This code will produce a clear and attractive table with an accompanying reference to that Cochrane review. One such 'effect of treatment' table is embedded in the Wikipedia page relevant to Early Intervention in Psychosis-Fig. 2 [15].

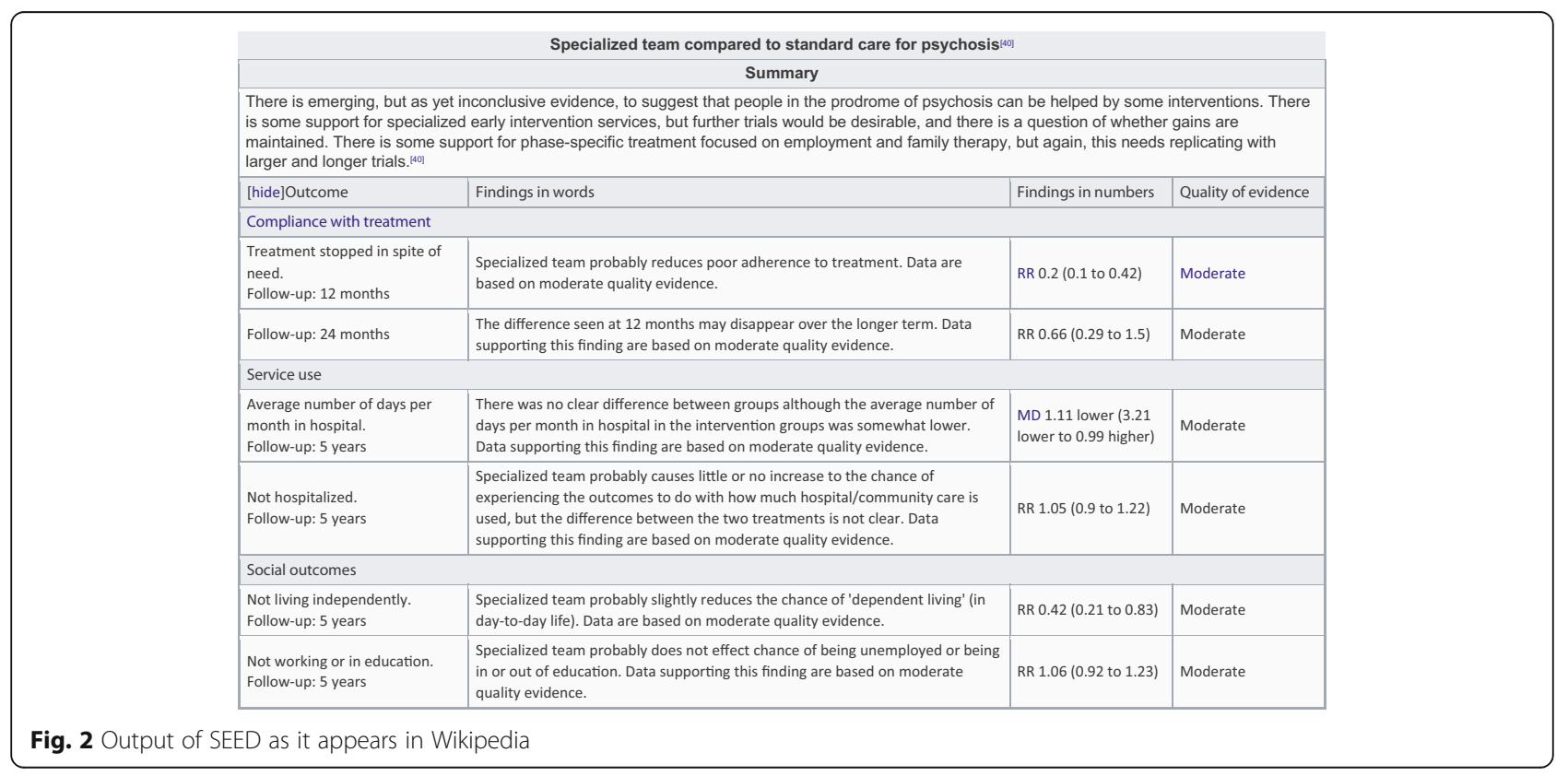




\section{Conclusions}

The time of researchers and staff involved in knowledge transfer is finite. As the reviewing process becomes more sophisticated and dissemination in one format is increasingly seen as inadequate more shortcuts will be needed to produce output. SEED is open-access (see Availability of data and materials, below) and greatly increases the efficiency of knowledge transfer into one highly-accessed format.

\section{Abbreviations}

EU: European Union; GUI: Graphical user interface; NIHR: National Institute of Health Research; SEED: Systematic EvidEnce Disseminator; SoF: Summary of Findings tables; XML: Extensible Markup Language

\section{Acknowledgements}

We acknowledge the use of the graphic of the Dandelion in Fig. 1 created by Alice Noir of the Noun Project (https://thenounproject.com/).

\section{Funding}

This work was supported though intramural UK NIHR funding along with EU Erasmus support for the student work experience.

\section{Availability of data and materials}

SEED is available to download-including the source code https:// github.com/CochraneSchizophrenia/SEED/releases/tag/FirstRelease. Examples of pages already containing SEED-produced expandable (press 'open') tables (static versions).

https://en.wikipedia.org/w/

index.php?title=Token_economy\&oldid=800992548.

https://en.wikipedia.org/w/index.php?title=Asenapine\&oldid=798881863.

https://en.wikipedia.org/w/index.php?title=Hypersalivation\&oldid=798766696.

\section{Authors' contributions}

LS undertook the main body of the programming and research into extraction from XML, undertook the testing and contributed to the write up. JF undertook the main body of the design of the graphical user interface, helped undertake the testing and contributed to the write up. CEA thought up the idea and did none of the programming but helped test and contributed to the write up. All authors read and approved the final manuscript.

\section{Ethics approval and consent to participate}

Not applicable.

\section{Consent for publication}

Not applicable.

\section{Competing interests}

The authors declare that they have no competing interests.

\section{Publisher's Note}

Springer Nature remains neutral with regard to jurisdictional claims in published maps and institutional affiliations.

\section{Author details}

${ }^{1}$ Hochschule Furtwangen University of Applied Sciences in Furtwangen im Schwarzwald, Furtwangen im Schwarzwald, Germany. ${ }^{2}$ University of Nottingham, Nottingham, UK. ${ }^{3}$ Institute of Mental Health, Jubilee Campus, University of Nottingham Innovation Park, Triumph Road, Nottingham NG7 2TU, UK.

Received: 15 August 2017 Accepted: 9 October 2017

Published online: 17 October 2017

\section{References}

1. Wikipedia: Size of Wikipedia. In: Wikipedia [Internet]. 2017 [cited 2017 Apr 10]. Available from: https://en.wikipedia.org/w/index.php?title=Wikipedia: Size_of_Wikipedia\&oldid=774170077.
2. Makovsky. Online Health Research eclipsing patient-doctor conversations [Internet]. 2013 [cited 2016 Apr 8]. Available from: http://www.makovsky. com/news/online-health-research-eclipsing-patient-doctor-conversations/.

3. Laurent M, Vickers T. Seeking health information online: does Wikipedia matter? J Am Med Inform Assoc. 2009;16(4):471-9.

4. Heilman J, West A. Wikipedia and medicine: quantifying readership, editors, and the significance of natural language. J Med Internet Res. 2015;17(3) [cited 2016 Aug 4]. Available from: https://www.ncbi.nlm.nih.gov/pmc/ articles/PMC4376174/

5. Wikipedia. Wikipedia:About [Internet]. Wikipedia:About. 2016 [cited 2016 Aug 4]. Available from: https://en.wikipedia.org/wiki/Wikipedia:About.

6. The Cochrane Collaboration | working together to provide the best evidence for health care [Internet]. [cited 2011 May 16]. Available from: http://www.cochrane.org/.

7. Higgins J, Green S, editors. Cochrane Handbook for Systematic Reviews of Interventions. In: 5.1.0. The Cochrane Collaboration; 2011 [cited 2016 Aug 4]. p. 1.2.2 What is a systematic review? Available from: http://handbook. cochrane.org/chapter_1/1_2_2_what_is_a_systematic_review.htm.

8. Cochrane Informatics and Knowledge Management Department. RevMan 5.3 [Internet]. 2014 [cited 2014 Jul 9]. Available from: http//tech.cochrane.org/Revman.

9. Burd B. Java for dummies. 4th ed. Foster City: IDG Books Worldwide; 2006. p. 365. United Kingdom

10. GRADEpro | GDT [Internet]. [cited 2017 Apr 10]. Available from: https:// gradepro.org/.

11. White D, Adams CE. What proportion of Cochrane Reviews are Wikicompatible? | Cochrane Community [Internet]. [cited 2017 Apr 10]. Available from: http://community.cochrane.org/news/what-proportion-cochranereviews-are-wiki-compatible.

12. Sense about Science-because evidence matters [Internet]. [cited 2017 Jul 10]. Available from: http://senseaboutscience.org/.

13. Help:Table. In: Wikipedia [Internet]. 2017. Available from: https://en. wikipedia.org/w/index.php?title=Help:Table\&oldid=789051822. Accessed 16 Oct 2017

14. Swing (Java). In: Wikipedia [Internet]. 2017. Available from: https://en. wikipedia.org/w/index.php?title=Swing_(Java)\&oldid=788349087. Accessed 16 Oct 2017.

15. Early intervention in psychosis. In: Wikipedia [Internet]. 2017. Available from: https://en.wikipedia.org/w/index.php?title=Early_intervention_in_ psychosis\&oldid=790208123. Accessed 16 Oct 2017.
Submit your next manuscript to BioMed Central and we will help you at every step:

- We accept pre-submission inquiries

- Our selector tool helps you to find the most relevant journal

- We provide round the clock customer support

- Convenient online submission

- Thorough peer review

- Inclusion in PubMed and all major indexing services

- Maximum visibility for your research

Submit your manuscript at www.biomedcentral.com/submit
Biomed Central 